\title{
ANISOTHERMAL HIGH-TEMPERATURE CYCLIC BEHAVIOR OF A Ni-BASED SINGLE CRYSTAL SUPERALLOY
}

\author{
Jean-Briac le Graverend ${ }^{1,2,3}$, Jonathan Cormier ${ }^{2}$, Franck Gallerneau ${ }^{3}$, Serge Kruch ${ }^{3}$, José Mendez ${ }^{2}$ \\ ${ }^{1}$ Texas A\&M University, Department of Aerospace Engineering, College Station, TX 77843, USA \\ ${ }^{2}$ Institut Pprime, CNRS - ENSMA - Université de Poitiers, UPR CNRS 3346, Physics and Mechanics of Materials Department, ENSMA - \\ Téléport 2, 1 avenue Clément Ader, BP 40109, 86961 Futuroscope Chasseneuil Cedex, France \\ ${ }^{3}$ Office National d'Etudes et de Recherches Aérospatiales, 29 avenue de la Division Leclerc, BP 72, 92322 Châtillon, France
}

Keywords: Ni-based Single-Crystal Superalloy, Creep, Anisothermal Loading, Cycling Loading, $\gamma$ ' Precipitation

\begin{abstract}
Dwell-fatigue tests and variable strain rate tensile tests followed by cycling tests were performed using $<001>$-oriented specimens made of a first-generation Ni-based single crystal superalloy. A short thermal jump from the nominal temperature of $1050^{\circ} \mathrm{C}$ to $1200^{\circ} \mathrm{C}$ was introduced along the lifetime of dwell-fatigue experiments and at the beginning of tensile tests. Once such thermal loading was applied, a fine $\gamma$ ' precipitation occurred in the $\gamma$ matrix and induced a large transient strengthening effect on the mechanical properties. Indeed, a transient decrease of the plastic strain rate, corresponding to a reduced magnitude in the hysteresis loops, was measured due to the temperature peak during the dwellfatigue experiments. In addition, a temperature peak produced a large hardening effect during the tensile tests since a hardening of $160 \mathrm{MPa}$ was created. These transient phenomena are due a temporary additional strengthening provided by fine $\gamma^{\prime}$ precipitates lasting for the time necessary for their dissolution.
\end{abstract}

\section{Introduction}

The development and exploitation of gas-turbine blades cast from nickel-base superalloys in single crystal form has been one of the most successful industrial and commercial ventures relating to advanced structural materials over the last twenty years. These components are used in the hot section of the aero-engine and landbased gas turbines and are therefore subjected to anisothermal hightemperature dwell-fatigue deformations either during in-service operations or severe certification procedures. Such extreme thermo-mechanical environment leads to phase transformations as well as stress and microstructure gradients which dramatically alter mechanical properties. Besides this, during in-service operation of twin engine helicopters, one of the two engines may unexpectedly stop. This implies a brutal temperature rise of up to around $1200^{\circ} \mathrm{C}$ in the high pressure turbine blades for the engine still operating. Such an event is now included in the certification procedures of turboshaft engines and is known as One Engine Inoperative (OEI) rating $[1,2]$. Consequently, creep or dwell-fatigue tests under isothermal conditions become insufficient to tackle the characterization of the mechanical properties in non-isothermal loading conditions. Better predictions of the mechanical behavior under these conditions are therefore required to increase engine efficiency and lower maintenance costs.

The high creep resistance of Ni-base single crystal superalloys is induced by the precipitation of a high volume fraction (close to $70 \%$ ) of the long-range ordered L1 $2 \gamma^{\prime}$ phase which appears as cubes coherently embedded in a face-centered cubic (fcc) solid solution $\gamma$ matrix [3] (see Figure 1(a)) and evolves into platelets by directional coarsening during high temperature mechanical testing $\left(\mathrm{T}>850^{\circ} \mathrm{C}\right)$ [4]. This volume fraction is modified during thermal changes above $\sim 850{ }^{\circ} \mathrm{C}$, which has a tremendous effect on the creep life [5], and depends on the temperature, the hold time and the applied load [6]. It was also recently noticed that an overheating at $1200{ }^{\circ} \mathrm{C}$ for 180 seconds performed on $<111>$ oriented specimens can induce a transient behavior during creep-fatigue experiments by introducing fine $\gamma^{\prime}$ precipitates within the $\gamma$ matrix [7] (see Figure 1(b)). Nevertheless, this transient behavior was never observed during non-isothermal creep loading on $<001>$ oriented samples [8]. The objective of this work is then to elucidate the role played by the fine $\gamma^{\prime}$ precipitates during non-isothermal cyclic loading when the viscoplastic behavior of Ni-base single crystal superalloys is out of equilibrium.

\section{Experimental Procedure}

\section{$\underline{\text { Material }}$}

Experiments were performed using the first-generation Ni-based single-crystal superalloy MC2. Its nominal composition is given in Table I. Experiments were carried out on specimens which had received the $\mathrm{MC} 2$ standard heat treatment $\left(3 \mathrm{~h} / 1300^{\circ} \mathrm{C} / \mathrm{air}-\right.$ quenched (AQ) $+6 \mathrm{~h} / 1080^{\circ} \mathrm{C} / \mathrm{AQ}+20 \mathrm{~h} / 870^{\circ} \mathrm{C} / \mathrm{AQ}$ ) leading to a $0.4-0.5 \mu \mathrm{m}$ average $\gamma^{\prime}$ precipitate size and to $\mathrm{a} \approx 70 \%$ precipitate volume fraction (a typical as-received microstructure is shown in Figure 3(a)) [9-11]. The testing specimens had a gage length of 14 $\mathrm{mm}$ with a prismatic section $6 \mathrm{~mm}$ wide and $2 \mathrm{~mm}$ thick and were oriented close to a $<001>$ crystallographic orientation (deviation less than $5^{\circ}$ ). All samples were machined from MC2 rods from the same heat master and were heat treated simultaneously (solution+aging heat treatments).

Table I. Chemical composition of MC2 nickel base single crystal superalloy (in wt.\%).

\begin{tabular}{cccccccc}
\hline $\mathrm{Ni}$ & $\mathrm{Cr}$ & $\mathrm{Co}$ & $\mathrm{Mo}$ & $\mathrm{W}$ & $\mathrm{Al}$ & $\mathrm{Ti}$ & $\mathrm{Ta}$ \\
\hline balance & 8.0 & 5.0 & 2.0 & 7.8 & 5.0 & 1.5 & 6.1 \\
\hline
\end{tabular}

Microstructural Characterization

Microstructural analyses were carried out using Zeiss 982 Gemini scanning electron microscope operating at $25 \mathrm{kV}$. The samples were cut parallel to the loading axis and mechanically polished up to a mirror finish. The $\gamma^{\prime}$ precipitates were revealed by selective dissolution of the $\gamma^{\prime}$ phase using a triacid etching solution of $66 \%$ $\mathrm{HCl}, 17 \% \mathrm{HNO}_{3}$ and $17 \% \mathrm{CH}_{3} \mathrm{COOH}$ at room temperature. Image processing was performed using Visilog ${ }^{\circledR}$ software which enhances the image features allowing better determination of different precipitates sizes and their volume fractions [12]. 


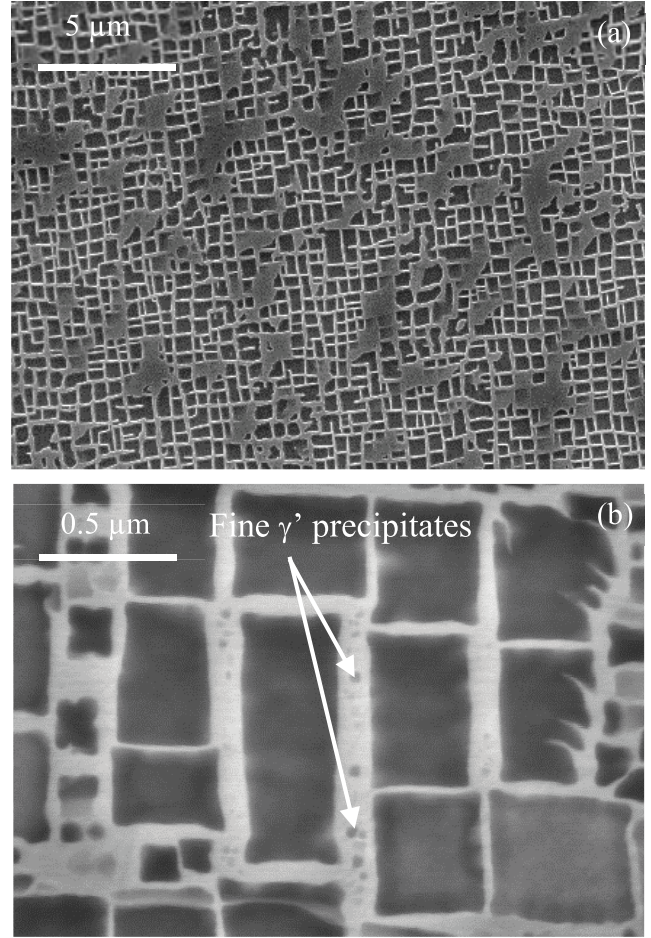

Figure 1. (a) As received microstructure of MC2 alloy highlighting a cuboidal $\gamma^{\prime}$ morphology. (b) Microstructure after an overheating of $180 \mathrm{~s}$ at $1200^{\circ} \mathrm{C}$ without an applied stress on a as-received microstructure.

\section{Mechanical Testing}

The thermo-mechanical tests were performed using an hydraulic machine equipped with an induction-heating system. The temperature was controlled using K-thermocouples spot-welded in the specimen heads in order to not induce any sources of damage in the gauge length. In addition, a pyrometer recorded the temperature in the middle of the gauge length. A temperature accuracy of $\pm 2^{\circ} \mathrm{C}$ was achieved with such a procedure [13]. Deformation was recorded and controlled using a 12-mm-gagelength axial extensometer with ceramic rods.

Dwell-fatigue experiments at $1050^{\circ} \mathrm{C}$ were performed using an asymmetric cycle, as shown in Figure 2. A thermal jump with no applied stress was introduced after a certain number of cycle sat-up using the experimental results obtained from creep experiments [14]. The complex tensile test at $1050^{\circ} \mathrm{C}$ consists of starting with a variable strain rate at $10^{-3} \mathrm{~s}^{-1}$ up to $1 \%$ of deformation, $10^{-5} \mathrm{~s}^{-1}$ from 1 to $1.5 \%, 10^{-3} \mathrm{~s}^{-1}$ from 1.5 to $2 \%$ (see Figure 3), then followed by

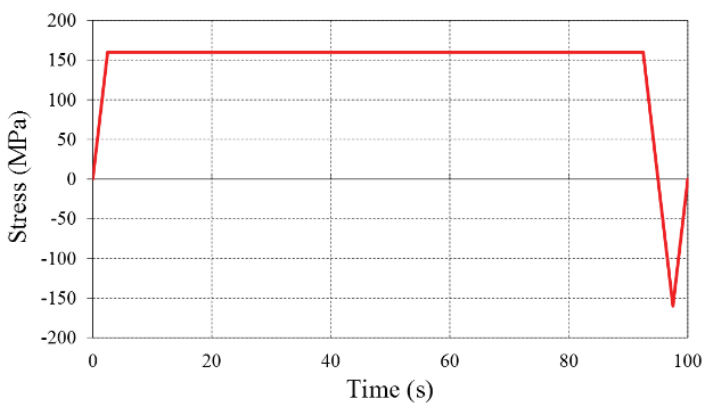

Figure 2. Mechanical cycle used to perform the creep-fatigue experiments at $1050^{\circ} \mathrm{C}$. fifty mechanical cycles at $10^{-3} \mathrm{~s}^{-1}$ between 2 and $1 \%$ (see Figure 4 ). Contrary to the dwell-fatigue experiments, two thermal jump durations were examined, viz. $30 \mathrm{~s}$ and $150 \mathrm{~s}$, in order to determine whether the influence of the fine $\gamma^{\prime}$ precipitates is dependent on a kinetics of dissolution.

\section{Results}

\section{Complex Tensile Tests: Variable Strain Rate - Cycling}

Variable strain rate tensile tests were performed at $1050{ }^{\circ} \mathrm{C}$. The mechanical behavior following an initial thermal jump of 30 s and $150 \mathrm{~s}$ is compared with the isothermal mechanical behavior (see Figure 3). It clearly reveals that the duration of the overheating does not matter since the two durations give the same results. However, a thermal jump before starting the tensile test strengthens the alloy by creating a large hardening of nearly $160 \mathrm{MPa}$ followed by perfectly plastic behavior. It also seems that the effect of the thermal jump does not impact the viscosity since the decrease in the strain rate from $10^{-3}$ to $10^{-5} \mathrm{~s}^{-1}$ leads to the same magnitude drop, namely about $150 \mathrm{MPa}$. Finally, the last loading at $10^{-3} \mathrm{~s}^{-1}$ shows the disappearance of the hardening induced by a thermal jump since all conditions give the same mechanical response. However, the first cycle of the cyclic loading performed at $10^{-3} \mathrm{~s}^{-1}$ between 1 and $2 \%$ shows a difference between the isothermal and the thermal jump conditions (see Figure 4(a)). Indeed, the isothermal cycle reaches $-183 \mathrm{MPa}$ as a minimum stress whereas the cycles for $30 \mathrm{~s}$ and 150 s reach -217 and $-209 \mathrm{MPa}$, respectively. This strengthened behavior vanishes by the fiftieth cycle, as shown in Figure 4(b). So, the strengthening effect brought about by an overheating is still effective after $535 \mathrm{~s}$ (end of the first cycle) but disappears after $1,515 \mathrm{~s}$ (end of the fiftieth cycle).

\section{Dwell-Fatigue Experiments}

Dwell-fatigue experiments were performed at $1050{ }^{\circ} \mathrm{C}$ and the mechanical cycle used is presented in Figure 2. A unique thermal jump of $30 \mathrm{~s}$ at $1200^{\circ} \mathrm{C}$ without applied stress was introduced after 0.33 hour/12 cycles, 2.4 hours/87 cycles and 4.5 hours/162 cycles. These three conditions will be subsequently named TJ 12 , TJ 87 , and TJ 162, respectively. The introduction of such a temperature jump, whatever its position in the isothermal dwell-fatigue life of the alloy, always led to a decrease in the time to failure in comparison with the pure isothermal condition (see Figure 5(a)). Indeed, the isothermal lifetime is 15.7 hours $/ 566$ cycles whereas it is only 6.4 hours/218 cycles, 8.1 hours/292 cycles, and 14.0

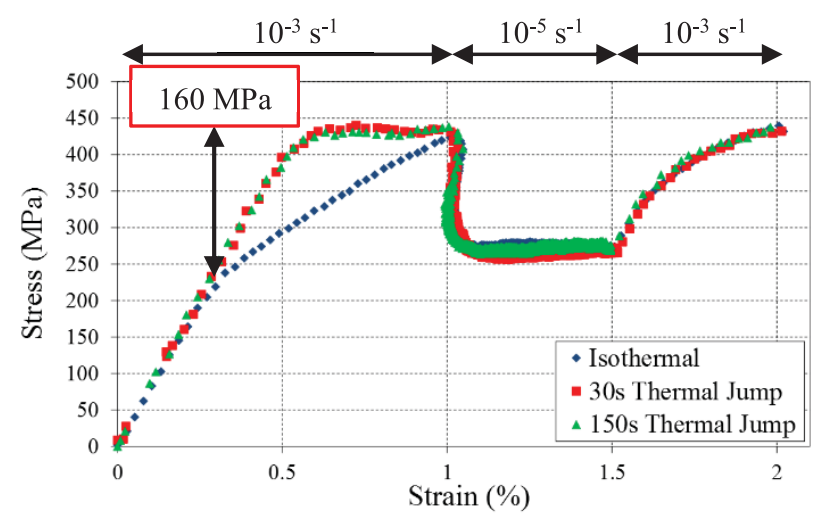

Figure 3. Variable strain rate tensile tests. Two thermal jump durations were studied, namely 30 s and 150 s. 

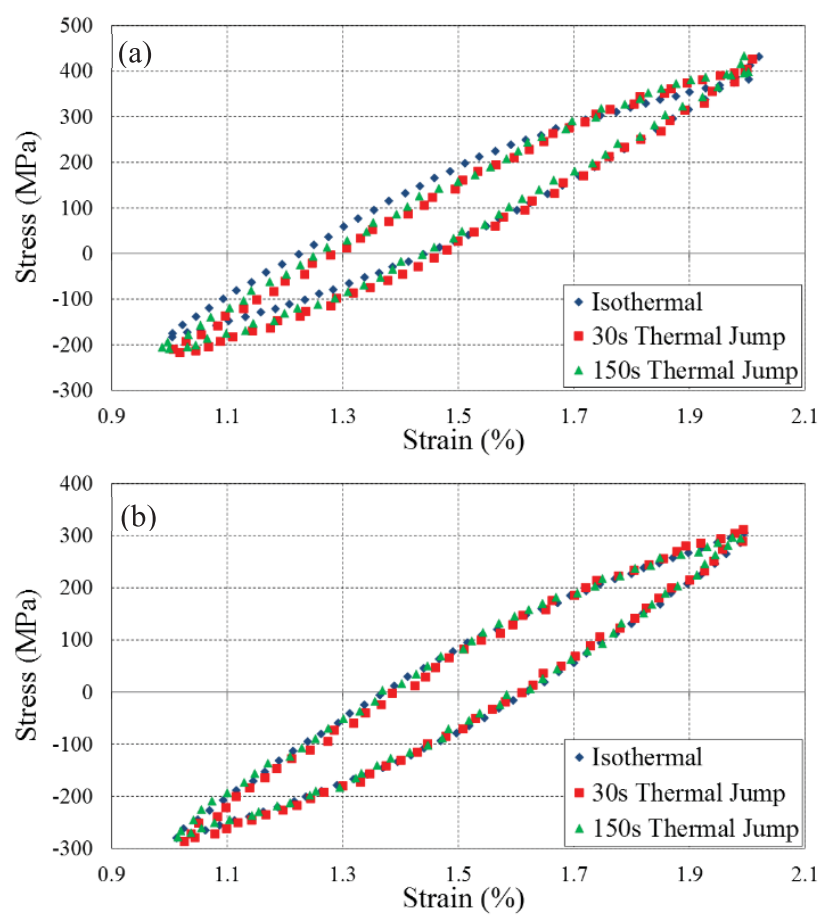

Figure 4. Strain controlled cyclic loading at $10^{-3} \mathrm{~s}^{-1}$ between 1 and $2 \%$ deformation performed after the variable strain rate tensile test shown in Figure 3(a) First cycle and (b) fiftieth cycle.

hours/506 cycles for TJ 12, TJ 87, and TJ 162, respectively. Furthermore, thermal jumps create a decrease in the plastic strain rate, as shown in Figure 5(b). As already discussed in the previous

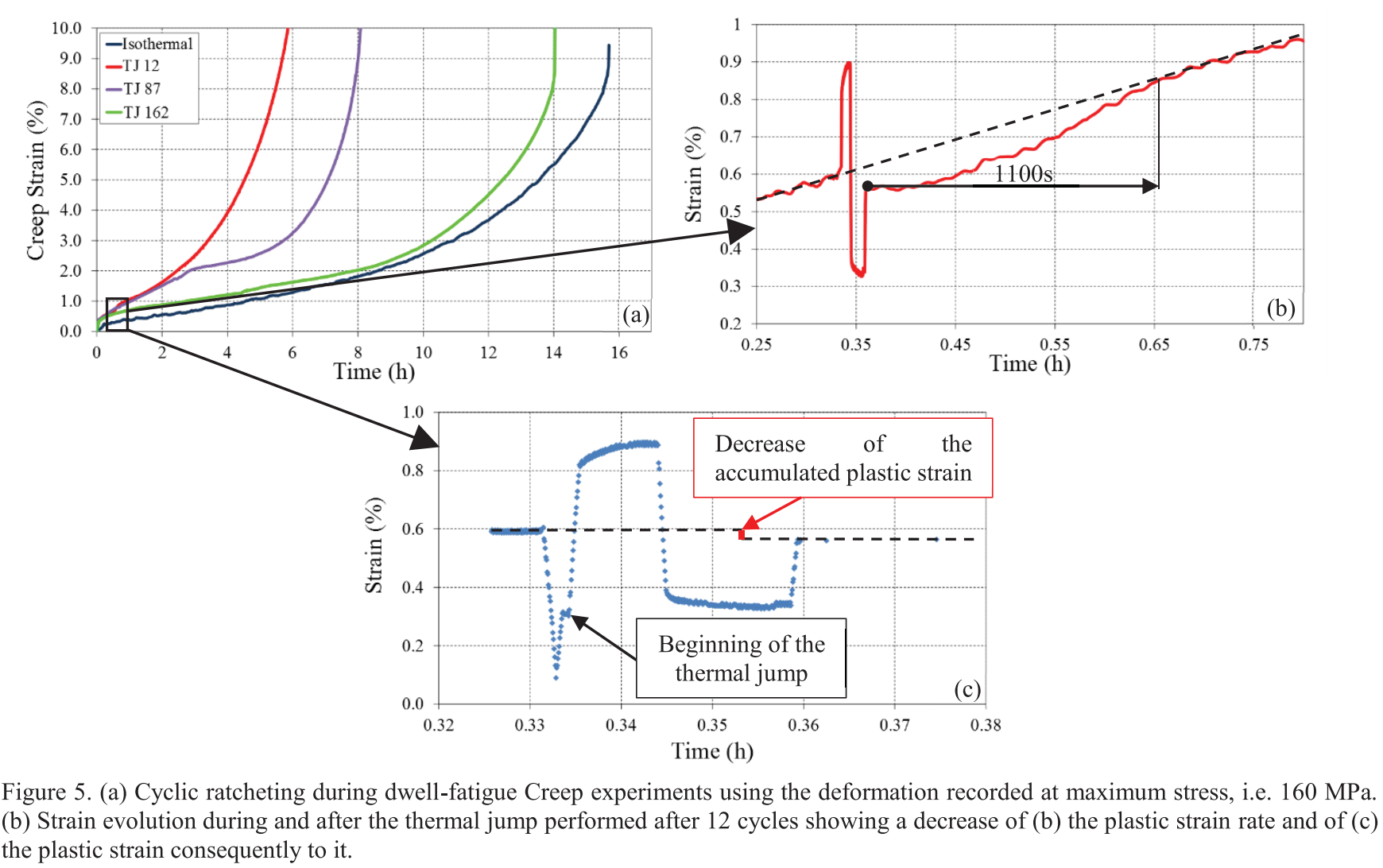

Figure 5. (a) Cyclic ratcheting during dwell-fatigue Creep experiments using the deformation recorded at maximum stress, i.e. $160 \mathrm{MPa}$. (b) Strain evolution during and after the thermal jump performed after 12 cycles showing a decrease of (b) the plastic strain rate and of (c) the plastic strain consequently to it. section, this strengthening effect is transient and may last up to $1,100 \mathrm{~s}$ in the case of a thermal jump introduced after 12 cycles. Thermal jumps also induce a decrease in the accumulated plastic strain since the starting strain after the overheating is lower than the one prior to it. This drop is in the order of $0.05 \%$ strain, as highlighted in Figure 5(c).

A fatigue-like representation allows us to extract additional cyclic ratcheting effect already observed in [15], explaining the evolution of the accumulated plastic strain in Figure 6(a). The hysteresis loop opening $\left(\Delta \varepsilon_{p}\right)$ is decreased after a thermal jump (Figure 6). It is the reason of the reduction in the plastic strain rate: the ratcheting rate is decreased. Most importantly, the shape of the loops highlights a negative plastification in the compressive portion prior to the overheating (see Figure 6(c)). This mechanical response is temporarily modified after a thermal jump since no negative plasticity is recorded for 47,82 , and 88 cycles when an overheating is introduced after 12,87 , and 162 cycles, respectively.

\section{Discussion}

\section{Creep vs. dwell-fatigue}

Few studies have been done on the stress-controlled interactions between creep and fatigue in Ni-based single crystal superalloys [16-21]. Contrary to EI 698 VD alloy under repeated loading at 650 ${ }^{\circ} \mathrm{C}[16]$ and to AM1 alloy under alternate loading at 950 and 1100 ${ }^{\circ} \mathrm{C}$ [17], the lifetime of isothermal dwell-fatigue experiments is not bounded by creep and fatigue lives in a Wöhler representation (creep life being the lower bound). Indeed, dwell-fatigue is much more damaging than creep, as shown in Figure 7(a) for which the life (93h). A similar result was obtained for polycrystalline information (see Figure 6). First, mechanical cycling creates a dwell-fatigue life (16h) is almost six times smaller than the creep 

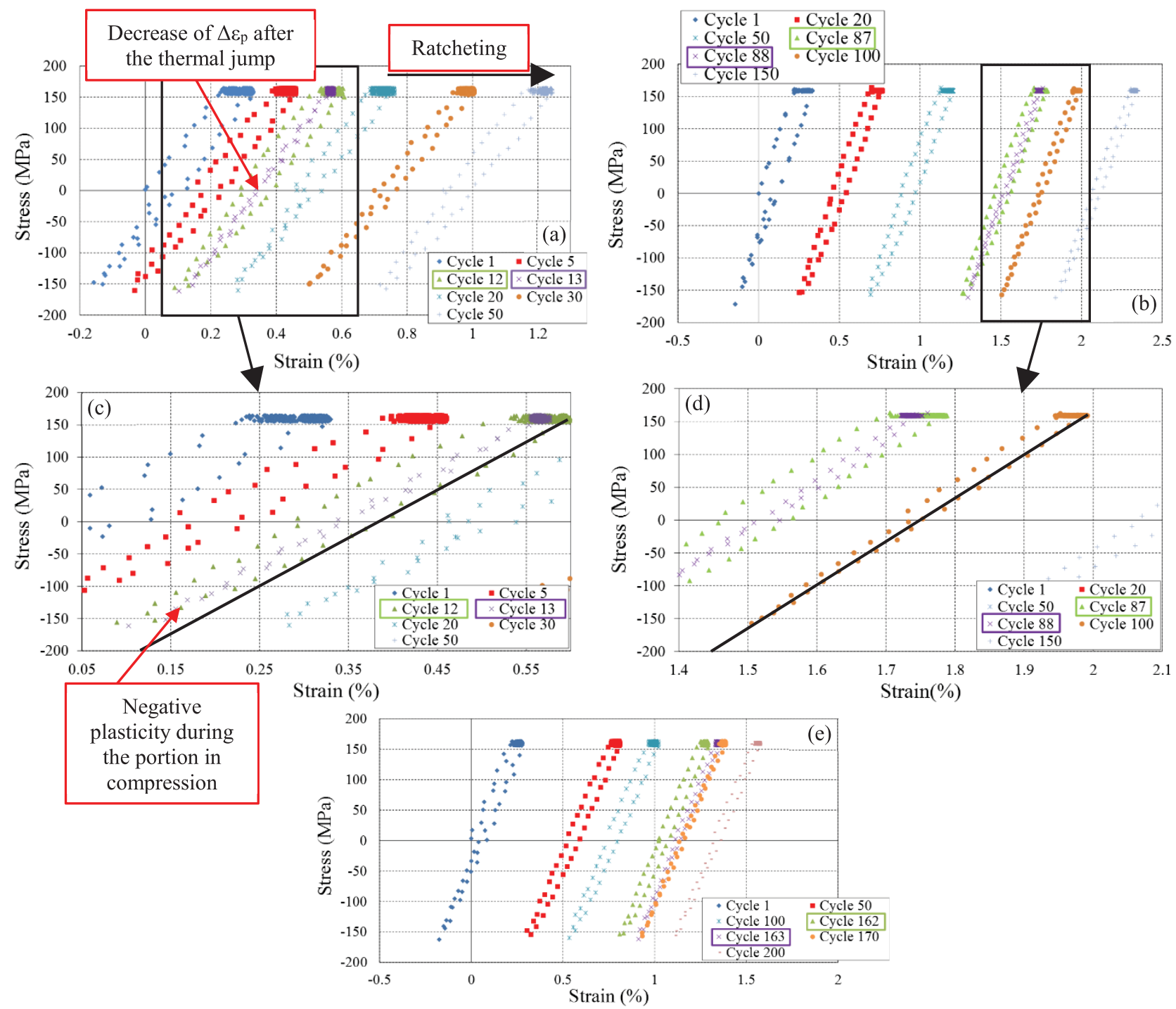

Figure 6. Stress-strain loops for the dwell-fatigue experiments with a thermal jump after (a) 12 cycles and (b) 87 cycles. (c) and (d) are the same loops that presented in (a) and (b), respectively, but centered on the loops before and after the thermal jump. (e) Stress-strain loops for the creep-fatigue experiments with a thermal jump after 162 cycles.
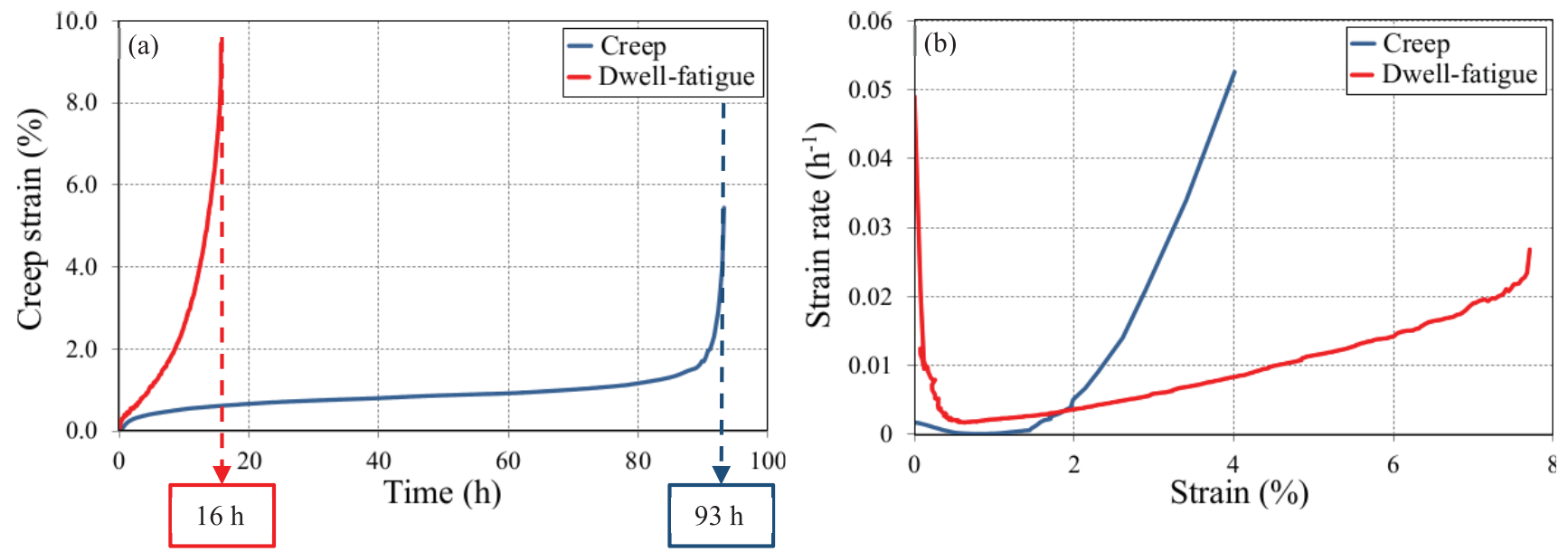

Figure 7. Comparison of (a) the creep deformations and (b) the strain rate evolutions (b) for the isothermal dwell-fatigue and creep experiments [24] at $1050^{\circ} \mathrm{C} / 160 \mathrm{MPa}$. 
superalloys, viz. N18 [22] and Udimet 720 [23], and even on a single crystal at $950{ }^{\circ} \mathrm{C}$ [19]. The authors attributed this phenomenon to a modification of the deformation mechanisms, namely a progressive transition from shearing (pure fatigue) to bypassing (pure creep) while increasing the hold time. In addition, compression is an aggravating factor concerning damage, as already shown for the polycrystalline materials GH4049 [25] and N18 [22] and for the single crystal AM1 [26]. It is due to a lower yield stress in compression than in tension for most of the single crystal superalloys [27]. It implies a greater shearing of the $\gamma$ ' particles in compression which is considered to be a damage mechanism responsible of the tertiary creep stage, namely an increase in the plastic strain rate leading to failure [28-30]. Finally, cracking is faster in fatigue in a $\gamma^{\prime}$-rafted microstructure perpendicular to the stress axis [31-33]. Indeed, once a crack is formed, it usually propagates along the $\gamma$-channels or the $\gamma / \gamma^{\prime}$ interfaces [34, 35] and avoids cutting the $\gamma^{\prime}$-phase for not forming highly energetic anti-phase boundaries (APB). Therefore, a microstructure formed during a dwell-fatigue test (Figure 8) with a positive mean stress is not appropriate for hindering crack propagation.

Compressive loading will not only bring a greater shearing of the $\gamma$ ' particles by the mobile dislocations, it will also allow pinned dislocations at $\gamma / \gamma^{\prime}$ interfaces to propagate again, as shown by Carroll et al. for the CMSX $-4^{\circledR}$ at 950 and $1020^{\circ} \mathrm{C}$ while switching the load in creep from tension to compression [36]. This depinning phenomenon is highlighted when comparing the duration of the transient decrease of the plastic strain rate after a thermal jump while performing repeated and alternate loadings at the same temperature/resolved shear stress condition. Indeed, the duration of the decrease of the plastic strain rate during repeated fatigue tests on $<111>$-oriented specimens was 3,000 s [7] whereas it was recorded to be about $1,000 \mathrm{~s}$ in the present study (alternate loading on $<001>$-oriented specimens). For equivalent temperature/resolved shear stress conditions, the shorter the duration of the transient decrease in the plastic strain rate is, the easier the shearing of $\gamma^{\prime}$ precipitates is. Therefore, alternate dwellfatigue loading leads to higher occurrence of $\gamma$ ' shearing and then causes a greater accumulation of the plastic strain compared to repeated loading. The difference in the mechanical behavior between creep and dwell-fatigue is also exposed in Figure 7(b). Indeed, contrary to creep experiencing a secondary creep stage between 0.4 and $1.5 \%$ strain, dwell-fatigue does not have such constant plastic strain rate regime but is in an accelerated plastic strain regime.

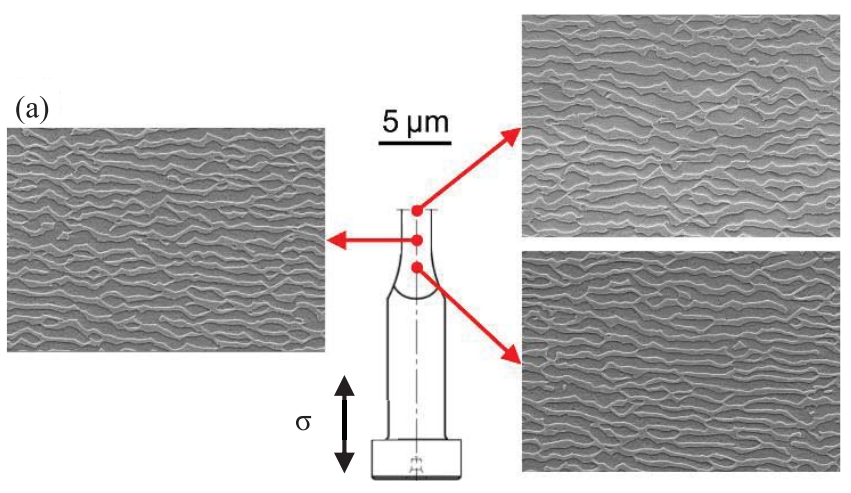

Effect of ultrafine $\gamma^{\prime}$ precipitates on the transient strengthening

The experimental results bring an insight into the effect of a short temperature peak at very high temperature $\left(\mathrm{T}>1150^{\circ} \mathrm{C}\right)$ on the cyclic response of $<001>$-oriented specimens made of Ni-based single crystal superalloys. In fact, thermal jump reduces the plastic strain rate for dwell-fatigue experiments. The same trend has been already observed along the $\langle 111\rangle$ orientation [7]. This phenomenon was attributed to the interactions between the fine $\gamma^{\prime}$ precipitates within the $\gamma$ channels and the mobile dislocations: $\gamma^{\prime}$ shearing is the main deformation mechanism for high resolved shear stress (RSS) whereas Orowan by-passing is for low RSS [37]. It was shown that a RSS of $62 \mathrm{MPa}$ for a $<111>$ orientation was necessary to trigger by-passing mechanisms. Therefore, a reasonable assumption was to consider that a dwell-fatigue experiment performed at a maximum of $151 \mathrm{MPa}$ on $<001>$ oriented specimens (Schmidt factor of 0.41 ) would create the proper condition to measure decreased plastic strain rate consequently to a thermal jump. The transient hardening measured in Figure 3 and Figure 6 after a thermal jump is due to a transient increase of the apparent yield stress (see Figure 3 ) caused by the fine $\gamma^{\prime}$ particles precipitating in the $\gamma$ channels and pinning dislocations for the time required for their dissolution [38, 39] or a size allowing $\gamma$ ' shearing [40]. Moreover, Kakehi also pointed out that the fine $\gamma$ ' precipitates play an important role in strengthening materials under creep at $700{ }^{\circ} \mathrm{C} / 820 \mathrm{MPa}$ by homogenizing strain, avoiding the creation of dislocation ribbons shearing the $\gamma$ and $\gamma^{\prime}$ particles through $<112>\{111\}$-type glide, and modifying the dissociation mode of the $\gamma$-phase dislocations in Shockley partial [41]. That leads to increased interactions between slip systems and therefore more hardening. So, $\gamma$ ' tertiary precipitation has an important effect on the mechanical behavior just after a thermal jump event, as already shown in isothermal conditions [42-44]. From Figure 3, the hardening can come from either an increase of the isotropic hardening and/or of the kinematic hardening, more specifically from its kinetics since its magnitude is unchanged by referring to the isothermal result, i.e. each experiments reach 440 $\mathrm{MPa}$ at $1 \%$ deformation. However, Figure 4 proves that there is an effect of the plastic strain history on the kinematic hardening, as shown in $[45,46]$ for steel, which is not the case for the isotropic hardening.

\section{High-temperature recovery process}

A decrease in the plastic strain observed after an overheating event is attributed to dynamic recovery processes. It is consistent with

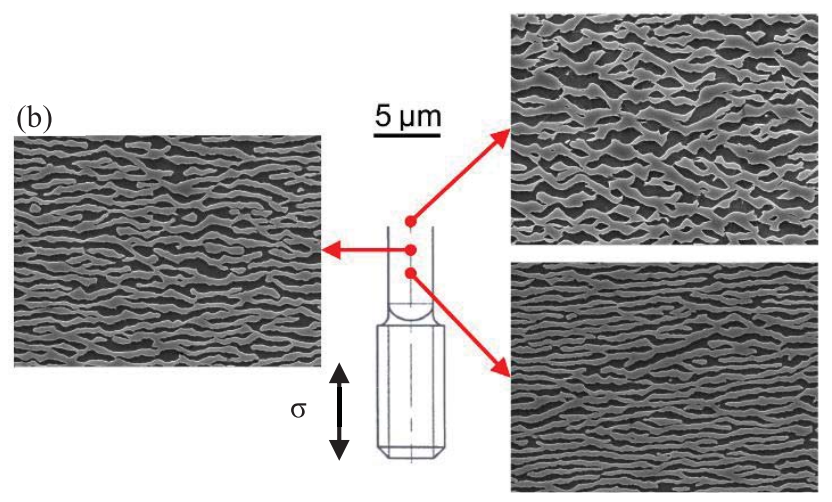

Figure 8. Microstructural observations every $2 \mathrm{~mm}$ from the rupture surface after (a) a creep-fatigue test at $1050^{\circ} \mathrm{C} / \sigma_{\max }=160 \mathrm{MPa}(\mathrm{tr}=16 \mathrm{~h}$ ) an after (b) a creep tests at $1050^{\circ} \mathrm{C} / 160 \mathrm{MPa}(\operatorname{tr}=218 \mathrm{~h})$ 
what was already measured during non-isothermal creep loading under synchrotron radiation [47, 48]. Indeed, high magnitude thermal jumps, viz. $\Delta \mathrm{T}>175^{\circ} \mathrm{C}$, for temperatures above $950{ }^{\circ} \mathrm{C}$ foster dynamic recovery processes leading to a decrease of the perpendicular lattice misfit, i.e. of the internal stresses, when the temperature comes back to its initial value. The following question is therefore raised: why are single thermal jumps not beneficial since all the conditions are aligned to improve the lifetime? Quickly dissolving the $\gamma^{\prime}$ phase during temperature peaks from $60 \%$ to $30 \%$ in volume fraction releases the $\gamma / \gamma$ ' interfacial dislocations $[49,50]$ within the $\gamma$ channels. The subsequent cooling creates a rapid growth of the $\gamma / \gamma^{\prime}$ interfaces which will therefore influence to the penetration of dislocations into the $\gamma$ ' phase [48]. This is commonly considered as a plastic mechanism responsible for the tertiary creep stage by increasing the plastic strain rate [51]. Thus, the damage induced by an overheating is essentially the increase of the plastic strain in the $\gamma^{\prime}$ phase $\left(\varepsilon_{\mathrm{p}}^{\gamma^{\gamma}}\right)$.

\section{$\underline{\text { Plasticity and precipitation }}$}

It is also of interest to notice that the longer the pre-cycling is, the shorter the decrease of the plastic strain rate is, despite a difference in the plastic strain: $0.3 \%$ for the TJ 12 experiment and $0.96 \%$ for the TJ 162 experiment (Figure 5). However, it is untrue when the stress-strain curves are considered (Figure 6). In fact, the decrease in the magnitude of the plastic strain is dependent on the level of plastic strain reached while inserting the thermal jump. This dependency seems to reach an asymptote, as the one obtained by Giraud et al. for the CMSX- $4{ }^{\circledR}[6]$. They showed that above a $0.33 \%$ of creep strain introduced at high temperature $\left(\mathrm{T}>900^{\circ} \mathrm{C}\right)$, the $\gamma / \gamma^{\prime}$ interfacial network is stabilized and there was no more effect of the plastic strain on the precipitation. Besides, the effect of dislocation network on diffusion processes was already reported in $[4,52]$. Interfacial dislocation networks foster the dissolution of the $\gamma^{\prime}$ phase and $\gamma$-channel dislocations are preferred sites for precipitation [53]. Thus, the difference between the number of cycles for which a decrease in the magnitude of the plastic strain has been recorded (Figure 6), i.e. 47, 81 and 87 cycles respectively for TJ 12,87 , and 162 , is due to the difference in the stabilization of dislocation networks.

\section{Conclusion}

Non-isothermal monotonic (complex tensile tests) and cyclic loading (dwell-fatigue) have been investigated in a first-generation Ni-base single crystal superalloy. Dwell-fatigue loading was recorded to be much more damaging than creep, especially because a compressive loading was applied which allowed a greater shearing of $\gamma^{\prime}$ precipitates and a depinning of dislocations. Furthermore, ultra-high thermal jumps created both recovery processes, leading to a decrease in the plastic strain, and ultrafine $\gamma$ ' precipitates nucleating upon cooling and strengthening the alloy by pinning the dislocations until the time necessary for their dissolution. From a modeling point of view, it was shown that fine $\gamma$ ' precipitation could modify both isotropic and kinematic hardening.

Fine $\gamma^{\prime}$ precipitation plays a key role in the non-isothermal mechanical behavior of Ni-based single crystal superalloys by modifying both monotonic and cyclic behaviors. Therefore, they have to be considered further in order to better predict the mechanical behavior and lifetime of structural components subjected to such intricate and harsh thermomechanical loading paths.

\section{Acknowledgments}

The authors are particularly grateful to Turbomeca - SAFRAN group for providing the material and to the DPAC (Direction des Programmes Aéronautiques et de la Coopération) for its financial suppport. This work is conducted under a French program involving Snecma-SAFRAN group, Turbomeca-SAFRAN group, ONERA and CNRS laboratories (Mines Paris Tech, Institut Pprime-ENSMA, LMT-Cachan, LMS-X, CIRIMAT-ENSIACET and CEAT). J.-B. le Graverend is also grateful to D. Pacou, V. Bonnand and R. Degeilh for stimulating discussions. Dr. Zéline Hervier (Materials Department at Turbomeca SAFRAN group) is gratefully acknowledged for her continuous interest in this work.

\section{REFERENCES}

1. F. Mauget et al. "Development and use of a new Burner Rig Facility to Mimic Service Loading Conditions of Ni-Based Single Crystal Superalloys", Eurosuperalloys 2014, 14, (2014).

2. J. Cormier et al. "Issues Related to the Constitutive Modeling of Ni-Based Single Crystal Superalloys under Aeroengine Certification Conditions", AerospaceLab Journal, (2015).

3. P. Caron. A Propos des Superalliages à Base de Nickel, Habilitation thesis for supervising research, Université Paris XI Orsay, (2005).

4. T.M. Pollock and A.S. Argon. "Directional Coarsening in Nickel-Base Single Crystals with High Volume Fractions of Coherent Precipitates", Acta Metallurgica \& Materialia, 42, (1994), 1859-1874.

5. T. Murakumo et al. "Creep Behaviour of Ni-Base SingleCrystal Superalloys with Various $\gamma^{\prime}$ Volume Fraction", Acta Materialia, 52, (2004), 3737-3744.

6. R. Giraud et al. "Strain Effect on the $\gamma^{\prime}$ Dissolution at High Temperatures of a Nickel-Based Single Crystal Superalloy", Metallurgical \& Materials Transactions A, 44, (2013), 131-146.

7. J.-B. le Graverend et al. "Effect of Fine $\gamma^{\prime}$ Precipitation on Non-isothermal Creep and Creep-fatigue Behaviour of NickelBase Superalloy MC2", Materials Science \& Engineering A, 527, (2010), 5295-5302.

8. J. Ghighi. A Microstructure Sensitive Approach for the Prediction of the Creep Behaviour and Life under Complex Loading Paths, PhD Thesis, ISAE-ENSMA, (2013).

9. A. Royer, P. Bastie and M. Véron. "In situ Determination of $\gamma^{\prime}$ Phase Volume Fraction and of Relations between Lattice Parameters and Precipitate Morphology in Ni-Based Single Crystal Superalloy", Acta Materiala, 46, (1998), 5357-5368.

10. K. Serin, G. Göbenli and G. Eggeler. "On the Influence of Stress State, Stress Level and Temperature on $\gamma$-channel Widening in the Single Crystal Superalloy CMSX-4", Materials Science \& Engineering A, 387-389, (2004), 133-137. 
11. M. Feller-Kniepmeier et al. "Temperature Dependence of Deformation Mechanisms in a Single Crystal Nickel-Base Alloy with High Volume Fraction of $\gamma^{\prime}$ Phase", Acta Materiala, 44, (1996), 2397-2407.

12. J. Cormier, X. Milhet and J. Mendez. "Effect of Very High Temperature Short Exposures on the Dissolution of the $\gamma^{\prime}$ Phase in Single Crystal MC2 Superalloy", Journal of Materials Science, 42, (2007), 7780-7786.

13. J. Cormier, X. Milhet and J. Mendez. "Non-isothermal Creep at Very High Temperature of the Nickel-Based Single Crystal Superalloy MC2", Acta Materiala, 55, (2007), 6250-6259.

14. J.-B. le Graverend et al. "Highly Non-linear Creep Life Induced by a Short close $\gamma^{\prime}$-Solvus Overheating and a prior Microstructure Degradation on a Nickel-Based Single Crystal Superalloy", Materials \& Design, 56, (2014), 990-997.

15. A. Staroselsky and B. Cassenti. "Creep, Plasticity, and Fatigue of Single Crystal Superalloy", International Journal of Solids \& Structures, 48, (2011), 2060-2075.

16. J. Zrnik et al. "Influence of the Hold Period on Creepfatigue Deformation Behaviour of Nickel Base Superalloy", Materials Science \& Engineering A, 319-321, (2001), 637-642.

17. F. Gallerneau and J.-L. Chaboche. "Fatigue Life Prediction of Single Crystals for Turbine Blade Applications", International Journal of Damage Mechanics, 8, (1999), 404-427.

18. S.X. Li and D.J. Smith. "High TemperatureFfatigueCreep Behaviour of Single Crystal SRR99 Nickel Base Superalloys: Part II-Fatigue-creep Life Behaviour", Fatigue and Fracture of Engineering Materials and Structures, 18, (1995), 631 643.

19. P. Perruchaut. Etude des Interactions Fatigue-fluageoxydation a $950{ }^{\circ} \mathrm{C}$ dans l'Endommagement du Superalliage Monocristallin AM1, PhD Thesis, Universite de Poitiers, (1997).

20. L. Thébaud et al. "Relationships between Microstructural Parameters and Time-Dependent Mechanical Properties of a New Nickel-Based Superalloy AD730 TM", Metals, 5, (2015), 22362251 .

21. D. Hu and R. Wang. "Experimental Study on CreepFatigue Interaction Behavior of GH4133B Superalloy", Materials Science \& Engineering A, 515, (2009), 183-189.

22. B. Flageolet et al. "On the Role of $\gamma$ Particles within $\gamma^{\prime}$ Precipitates on Damage Accumulation in the P/M Nickel-Base Superalloy N18", Materials Science \& Engineering A, 399, (2005), 199-205.

23. T. Billot et al. "Creep-Fatigue Behavior at High Temperature of a UDIMET 720 Nickel-Base Superalloy", International Journal of Fatigue, 32, (2010), 824-829.

24. J.-B. le Graverend et al. "Microstructural Parameters Controlling High-Temperature Creep Life of the Nickel-Base Single-Crystal Superalloy MC2", Metallurgical \& Materials Transactions A, 43, (2012), 3988-3997.
25. L.J. Chen et al. "Fatigue and Creep-Fatigue Behavior of a Nickel-Base Superalloy at $850{ }^{\circ} \mathrm{C} "$, International Journal of Fatigue, 20, (1998), 543-548.

26. P. Perruchaut, P. Villechaise and J. Mendez. "Some Aspects of Environmental Effects on the Fatigue Damage of the AM1 Single Crystal Superalloy at High Temperature", Second International Conference on Corrosion-Deformation Interactions, Ed. (1996), 342-353.

27. M. Yamashita and K. Kakehi. "Tension/Compression Asymmetry in Yield and Creep Strengths of Ni-Based Superalloy with a High Amount of Tantalum", Scripta Materialia, 55, (2006), 139-142.

28. D.W. MacLachlan and D.M. Knowles. "Creep-Behavior Modeling of the Single Crystal Superalloy CMSX-4", Metallurgical \& Materials Transactions A, 31, (2000), 1401-1411.

29. D.W. MacLachlan, G.S.K. Gunturi and D.M. Knowles. "Modelling the Uniaxial Creep Anisotropy of Nickel Base Single Crystal Superalloys CMSX-4 and RR2000 at 1023 K using a Slip System Based Finite Element Approach", Computational Materials Science, 25, (2002), 129-141.

30. A. Kostka et al. "L12 Phase Cutting during High Temperature and Low Stress Creep of a Re-containing Ni-Base Single Crystal Superalloy", Journal of Materials Science, 42, (2007), 3951-3957.

31. S.H. Ai, V. Lupinc and G. Onofrio. "Influence of Precipitate Morphology on High Temperature Fatigue Crack Growth of a Single Crystal Nickel Base Superalloy", Scripta Metallurgica et Materialia, 29, (1993), 1385-1390.

32. H. Mughrabi, S. Kraft and M. Ott. "Specific Aspects of Isothermal and Anisothermal Fatigue of the Monocristalline Nickel-Base Superalloy CMSX-6", Superalloys 1996, Ed. Kissinger, R. D., et al., (1996), 335-344.

33. M. Ott and H. Mughrabi. "Dependence of the HighTemperature Low-Cycle Fatigue Behaviour of the Monocristalline Nickel-base Superalloys CMSX-4 and CMSX-6 on the $\gamma / \gamma^{\prime}-$ Morphology", Materials Science \& Engineering A, 272, (1999), 24-30.

34. M.B. Henderson and J.W. Martin. "Influence of Precipitate Morphology on the High Temperature Fatigue Properties of SRR99", Acta Metallurgica et Materialia, 43, (1995), 4035-4043.

35. B.A. Lerch and S.D. Antolovich. "Fatigue Crack Propagation Behavior of a Single Crystalline Superalloy", Metallurgical Transactions A, 21, 2169-2177.

36. M.C. Carroll, K. Serin and G. Eggeler. "Anisotropic Strain Hardening following Load Reversal during HighTemperature Creep Testing of Superalloy Single Crystals", Material Science \& Engineering A, 387--389, (2004), 590-594.

37. B.H. Kear et al. "Slip and Climb Processes in $\gamma^{\prime}$ Precipitation Hardened Nickel-Base Alloys", Scripta Metallurgica, 2, (1968), 287-293. 
38. G. Cailletaud and J.-L. Chaboche. "Macroscopic Description of the Microstructural Changes Induced by Varying Temperature: Example of IN100 Cyclic Behavior", Mechanical behavior of materials, 2, (1979), 23-32.

39. D.W. MacLachlan et al. "Modelling the Anisotropic and Biaxial Creep Behaviour of Ni-Base Single Crystal Superalloys CMSX-4 and SRR99 at 1223K", Superalloys 2000, Ed. Pollock, T. M., et al., (2000), 357-366.

40. V. Mohles, D. Ronnpagel and E. Nembach. "Simulation of Dislocation Glide in Precipitation Hardened Materials", Computational Materials Science, 16, (1999), 144-150.

41. K. Kakehi. "Effect of Primary and Secondary Precipitates on Creep Strength of Ni-Base Superalloy Single Crystals", Materials Science \& Engineering A, 278, (2000), 135-141.

42. M. Soucail and Y. Bienvenu. "Dissolution of the $\gamma^{\prime}$ Phase in a Nickel Base Superalloy at Equilibrium and under Rapid Heating", Material Science \& Engineering A, 220, (1996), 215222.

43. S.S. Babu et al. "Characterization of the Microstructure Evolution in a Nickel Base Superalloy during Continuous Cooling Conditions", Acta Materiala, 49, (2001), 4149-4160.

44. A.M. Brass, D. Roux and J. Chene. "Role of Secondary $\gamma^{\prime}$ Precipitation and of Hydrogen in the First Stage of the Plastic Deformation of the $\gamma$ Matrix of a Ni Base Superalloy Single Crystal", Material Science \& Engineering A, 323, (2002), 97-102.

45. D. Marquis. Etude Theorique et Verification Experimentale d'un Modele de Plasticite Cyclique, Ph.D. Thesis, Universite Pierre et Marie Curie, Paris VI, (1979).

46. J.-L. Chaboche, K. Dang Van and G. Cordier. "Modelization of the Strain Memory Effect on the Cyclic Hardening of 316 Stainless Steel". in: Jaeger, T. A., et al., (Eds.). Structural Mechanics in Reactor Technology. Berlin, 1979.

47. J.-B. le Graverend et al. "In situ Measurement of the $\gamma / \gamma^{\prime}$ Lattice Mismatch Evolution of a Nickel-Based Single-Crystal Superalloy during Non-isothermal Very High-Temperature Creep Experiments", Metallurgical \& Materials Transactions A, 43, (2012), 3946-3951.

48. J.-B. le Graverend et al. "Creep of a Nickel-based SingleCrystal Superalloy during Very High-Temperature Jumps Followed by Synchrotron X-ray Diffraction", Acta Materialia, 84, (2015), 65-79.

49. M. Probst-Hein, A. Dlouhy and G. Eggeler. "Interface Dislocations in Superalloy Single Crystals", Acta Materiala, 47, (1999), 2497-2510.

50. T. Sugui et al. "Aspects of Primary Creep of a Single Crystal Nickel-Base Superalloy", Material Science \& Engineering A, 262, (1999), 271-278.

51. T. Sugui et al. "Formation and Role of Dislocation Networks during High Temperature Creep of a Single Crystal Nickel-Base Superalloy", Materials Science \& Engineering A, 279, (2000), 160-165.
52. O. Paris et al. "Early Stages of Precipitate Rafting in a Single Crystal Ni-Al-Mo Model Alloy Investigated by SmallAngle X-ray Scattering and T.E.M", Acta Materialia, 45, (1997), 1085-1097.

53. J.Y. Buffière and M. Ignat. "A Dislocation based Criterion for the Raft Formation in Nickel-Based Superalloys Single Crystals", Acta Metallurgica \& Materialia, 43, (1995), 1791-1797. 